\title{
Cross-Validation and Reliability of THE Line-Drill Test of Anaerobic Performance in Basketball Players 14-16 Years
}

\author{
Humberto M. Carvalho, ${ }^{1}$ Manuel J. Coelho e Silva, ${ }^{1}$ António J. Figueiredo, ${ }^{1}$ \\ Carlos E. Gonçalves, ${ }^{1}$ Carlo Castagna, ${ }^{2}$ Renati M. Philippaerts, ${ }^{3}$ \\ and Robert M. Malina ${ }^{\mathbf{4 , 5}}$ \\ ${ }^{1}$ Faculty of Sports Sciences and Physical Education, University of Coimbra, Coimbra, Portugal; ${ }^{2}$ Faculty of Medicine and \\ Surgery, School of Sport and Exercise Sciences, University of Rome Tor Vergata, Rome, Italy; ${ }^{3}$ Department of Movement and \\ Sports Sciences, Faculty of Medicine and Health Sciences, Ghent University, Gent, Belgium; ${ }^{4}$ Department of Health and Physical \\ Education, Tarleton State University, Stephenville, Texas; and ${ }^{5}$ Department of Kinesiology and Health Education, University of \\ Texas at Austin, Austin, Texas
}

\begin{abstract}
Carvalho, HM, Coelho e Silva, MJ, Figueiredo, AJ, Gonçalves, CE, Castagna, C, Philippaerts, RM, and Malina RM. Cross-validation and reliability of the line-drill test of anaerobic performance in basketball players 14-16 years. J Strength Cond Res 25(4): 1113-1119, 2011-This study evaluates the validity and reliability of the line-drill (LD) test of anaerobic performance in 76 male basketball players $14.0-16.0$ years of age. The Wingate Anaerobic Test (WAnT) was used as the reference for anaerobic performance. Wingate Anaerobic Test and LD test were moderately correlated (0.39 and 0.43, $p<0.01)$. Estimated age at peak height velocity (APHV) was moderately, negatively, and significantly $(p<0.01)$ correlated with WAnT peak $(r=-0.69)$ and mean power $(r=-0.71)$; earlier-maturing players had greater anaerobic power. Training experience was not associated with anaerobic performance, but chronological age (CA) and estimated APHV were significant covariates of the LD test $(p<0.05)$. National players were better than local players on the LD test $(p<0.01)$ after controlling for CA and body size. Short-term reliability of the LD test $(n=12,1$-week interval) was good: technical error of measurement $=0.44$ seconds (95\% confidence interval [Cl] 0.31-0.75 seconds), intraclass correlation coefficient $=0.91(95 \% \mathrm{Cl} 0.68-0.97)$, and coefficient of variation $=1.4 \%(95 \% \mathrm{Cl} 1.0-2.3 \%)$. Although the relationship between the LD test and WAnT was moderate, the LD test effectively distinguished local- and
\end{abstract}

Address correspondence to Humberto M. Carvalho, hmoreiracarvalho@ gmail.com.

25(4)/1113-1119

Journal of Strength and Conditioning Research

(c) 2011 National Strength and Conditioning Association national-level adolescent basketball players. In contrast to WAnT, the LD test was not influenced by estimated biological maturity status. Thus, the LD test may be suitable for field assessment of anaerobic performance of youth basketball players.

KEY WoRDs adolescents, athletes, field testing, biological maturation, maturity offset

\section{INTRODUCTION}

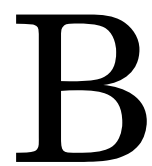

asketball, as many other team sports, involves short, intense, and repeated episodes of activity that require rapid changes in direction $(6,25,29)$. The physical demands of basketball vary with age of athletes, level of competition, and coaching strategies. Given the intermittent nature of basketball (29), the physiological requirements of the sport place major demands on the cardiovascular and metabolic capacities of the players. Although the majority of play time is devoted to activities aerobic in nature $(6,37)$, anaerobic metabolism makes an important contribution to the energy demands of basketball (6). Anaerobic performance is a predictor of playing time in youth (19) and of playing level (34) in adults.

Field tests of aerobic endurance have been validated in presenior basketball players (11). In contrast, anaerobic fitness has been ordinarily measured with the laboratory-based Wingate Anaerobic Test (WAnT), which has reasonable reproducibility in adolescent athletes (5). However, its specificity for athletes in noncycling sports has not been established.

Several repeated-sprint tests have been proposed for the field assessment of anaerobic performance $(22,36,43)$. The line-drill test (LD) has been proposed as a viable and practical test of the anaerobic performance of basketball players in field conditions (35). Although there is interest in the LD test 
and emerging evidence of its applicability to anaerobic fitness assessment $(2,11,17,18,31)$, most of the available data were collected using manual chronometers, which may be a source of variability in estimates of reliability and validity.

Physiological tests are often included in talent identification test batteries using a multidimensional approach $(12,33,40)$. Mid- to late adolescence in male players, about 14-16 years, is often considered as an initial phase for prediction of success in basketball and other team sports (32), in part, because most boys have progressed through the adolescent growth spurt, although interindividual variability is considerable (28). It is possible that the concurrent validity between laboratory and sport-specific field tests is affected by maturity status of adolescent players in addition to chronological age (CA) per se and years of training in the sport.

The purpose of the present study was to determine the reliability of the 140-m LD field test of anaerobic performance and to examine its relationship with the WAnT in youth basketball players 14-16 years of age. The study also examines the relationships between the anaerobic tests controlling for $\mathrm{CA}$, years of training, and estimated biological maturity status, and the effectiveness of the field and laboratory protocols to distinguish adolescent basketball players by competitive level (construct validity).

\section{Methods}

\section{Experimental Approach to the Problem}

The study is cross-sectional in design. Given the importance of anaerobic energy supply (34) and basketball-specific movement demands $(6,29)$, a running field test involving shuttle running over $28 \mathrm{~m}$ (approximately court length) as in the $\mathrm{LD}$ test may be a practical alternative to laboratory assessments of anaerobic capacity in basketball.

Reliability in the LD test was based on replicate tests in a subgroup within a period of 3-5 days. To examine criterion validity, $\mathrm{LD}$ performance was compared with WAnT power outputs, using the latter as criterion or gold standard. After reliability and criterion validity were established, construct validity was examined by comparing anaerobic performance of adolescent basketball players of different competitive levels. Additionally, CA, years of training in basketball, and estimated biological maturity status were statistically controlled to determine if criterion validity and concurrent validity between laboratory and sport-specific field tests were affected by maturation in addition to age and years of training in the sport.

\section{Subjects}

The sample included 76 male basketball players 14.016.0 years of age at the time of testing. All players were of Portuguese ancestry except for 4 who were of African ancestry. Players were classified as under 16 (U16) by the Federação Portuguesa de Basquetebol (Portuguese Basketball Federation). Two competitive levels were represented in the sample: national and local. The former included 24 players who regularly trained at the national center for elite basketball players, whereas the latter included 52 players from 5 locallevel clubs. Participation in the study was voluntary. Each participant's parents or legal guardians provided written informed consent before participation in the study. Players also provided informed consent. The nature of the study and any possible risks associated with participation were explained to the youth and parents in compliance with the Declaration of Helsinki. All procedures were approved by the Scientific Committee of the Faculty of Sport Science and Physical Education of the University of Coimbra.

\section{Procedures}

Chronological age was recorded to the nearest 0.1 year by subtracting birth date from the date of the mid-testing period. The variables considered in this study were part of a larger battery of observations made on the players over a 1-month interval. Stature and sitting height were measured with a portable stadiometer (Harpenden model 98.603; Holtain, Ltd., Crosswell, United Kingdom) to the nearest $0.1 \mathrm{~cm}$. Body mass was measured with a portable balance (Seca model 770; Seca, Hanover, MD, USA) to the nearest $0.1 \mathrm{~kg}$. Leg (subischial) length was estimated as stature minus sitting height. Anthropometric dimensions were measured by a single individual following the procedures described by Lohman et al. (26). Intra-observer technical errors of measurement (TEM) for height, sitting height, and weight were $0.27 \mathrm{~cm}, 0.31 \mathrm{~cm}$, and $0.47 \mathrm{~kg}$, respectively, which were well within the range of intra- and interobserver errors in several surveys in the U.S.A. and a variety of field studies of young athletes (27).

Age at peak height velocity (APHV) was estimated with the maturity offset protocol (30). The technique estimates time before or after peak height velocity (PHV) from CA, height, sitting height, and estimated leg length (height minus sitting height) in centimeters, and weight in kilograms as follows:

Maturity offset $=-9.236+[0.0002708$

$\times($ leg length $\times$ sitting height $)]+[-0.001663$

$\times($ age $\times$ leg length $)]+[0.007216 \times($ age $\times$ sitting height $)]$

$+[0.02292 \times([$ weight $/$ height $] \times 100)]$

Negative values indicated time before PHV and positive values time after PHV. Negative offset values were added to and positive offset values were subtracted from $\mathrm{CA}$ to estimate APHV.

Years of training was obtained by interview and confirmed in the online database of the Federação Portuguesa de Basquetebol (14).

\section{Anaerobic Testing}

Subjects were instructed not to eat for at least 3 hours before each testing session and not to drink coffee or beverages containing caffeine for at least 8 hours before testing. Assessments were made at the same time of the day 
Journal of Strength and Conditioning Research $\mid$ www.nsca-jscr.org

(6:00-7:00 PM for field tests, 3:00-6:00 PM for laboratory tests). Subjects wore similar clothing and the same footwear on each testing occasion.

The anaerobic tests were completed within a 2-week period, with at least 48 hours between test sessions. Data collection for national-level players occurred in the last week of September, the early phase of the season. Data collection for local-level players was completed during a pre-competitive period in December.

After a standardized warm-up, athletes completed the 30 second WAnT test (23) on a friction-loaded cycle ergometer (Monark 824E; Monark AB, Varberg, Sweden) that was interfaced with a microcomputer and calibrated for pedal speed and applied resistance. The resistance was set at $0.075 \mathrm{~kg}$ $(0.74 \mathrm{~N})$ body mass. Wingate Anaerobic Test began with minimal resistance (basket supported) at $60 \mathrm{rpm}$. On the command "go," the resistance was applied abruptly and simultaneously the computer was activated. Athletes remained seated during the test and were verbally encouraged for an allout effort throughout the test. Measurements included anaerobic peak power (PP; highest mechanical power generated any 5 -second period) and mean power (MP; average for the 30-second period). Both were expressed as watts.

In the $\mathrm{LD}$ protocol, subjects ran $140 \mathrm{~m}$ as fast as possible in the form of 4 consecutive shuttle sprints of 5.8, 14.0,22.2, and $28.0 \mathrm{~m}$ on a regulation basketball court. Athletes began the test behind a starting gate of photoelectric cells (Globus Ergo Timer Timing System; Globus, Codognè, Italy) set at $1 \mathrm{~m}$ of the baseline of the basketball court. Time was recorded by the split gate placed on the baseline where athletes changed directions in the shuttle runs (Figure 1). Verbal encouragement for an all-out effort was given throughout the test.

\section{Statistical Analyses}

Descriptive statistics for CA, training experience, anthropometric dimensions, estimated APHV, and anaerobic performance were calculated. The assumption of normality was checked by the KolmogorovSmirnov test, with Lilliefors' significance correction, and by visual inspection of normality plots. No assumptions were violated.

The TEMs, coefficients of variation $(\mathrm{CVs})$, and intraclass correlation coefficients (ICCs) were calculated based on the replicate tests of anaerobic performance (20). Uncertainty in the difference between the first and second trials was expressed as the $95 \%$ confidence interval $(\mathrm{CI})$. Data were

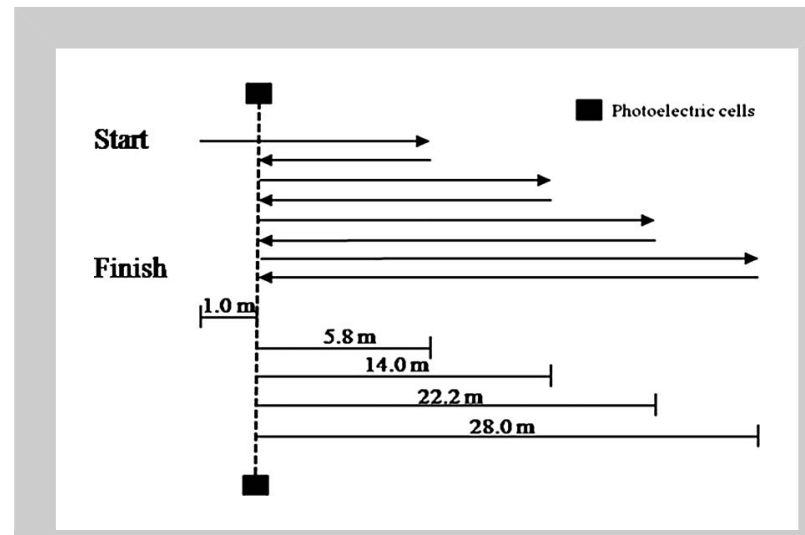

Figure 1. Course for the line-drill test.

checked for heteroscedasticity using plots of the log-transformed data, and reliability measurements (absolute and percent typical errors) were calculated (9).

Pearson correlations were calculated between each anaerobic indicator (LD, PP, and MP) and CA, estimated APHV, and training experience. Correlations between the field (LD) and laboratory (PP and MP) anaerobic indicators were calculated first as zero order and then as partial correlations controlling first for $\mathrm{CA}$ and estimated APHV and then for CA, stature, and body mass. Using Hopkins (21) as a guide, correlations were considered as trivial $(r<0.1)$, small $(0.1<r$ $<0.3)$, moderate $(0.3<r<0.5)$, large $(0.5<r<0.7)$, very large $(0.7<r<0.9)$, and nearly perfect $(r>0.9)$.

Anaerobic indicators (LD, PP, and MP) were also compared between elite and local-level players using one-way analysis of variance and analysis of covariance (ANCOVA; with CA, estimated APHV, and body size as covariates). Significance was set at $p \leq 0.05$. Statistical analyses were performed using SPSS version 17.0 software (SPSS, Inc., Chicago, IL, USA).
TABLE 1. Descriptive statistics for the total sample $(n=76)$.*

\begin{tabular}{lccc}
\hline & Mean & $S D$ & Range \\
\hline Chronological age (y) & 15.2 & 0.5 & $14.0-16.0$ \\
Years of formal training & 5.9 & 2.5 & $1.0-11.0$ \\
Stature (cm) & 177.7 & 9.5 & $155.1-197.2$ \\
Sitting height (cm) & 92.4 & 4.7 & $80.9-103.2$ \\
Estimated leg length (cm) & 85.4 & 5.4 & $72.5-99.0$ \\
Body mass (kg) & 68.2 & 9.5 & $44.6-104.5$ \\
Maturity offset (y) & 1.8 & 0.8 & $-0.23-3.36$ \\
Estimated age at PHV (y) & 13.4 & 0.7 & $12.0-15.0$ \\
Line-drill test (s) & 31.02 & 1.39 & $28.43-35.20$ \\
WAnT peak power (W) & 642.3 & 130.0 & $357-1,011$ \\
WAnT mean power (W) & 551.3 & 108.7 & $312-917$ \\
\hline
\end{tabular}

${ }^{*} \mathrm{WAnT}=$ Wingate Anaerobic Test. 


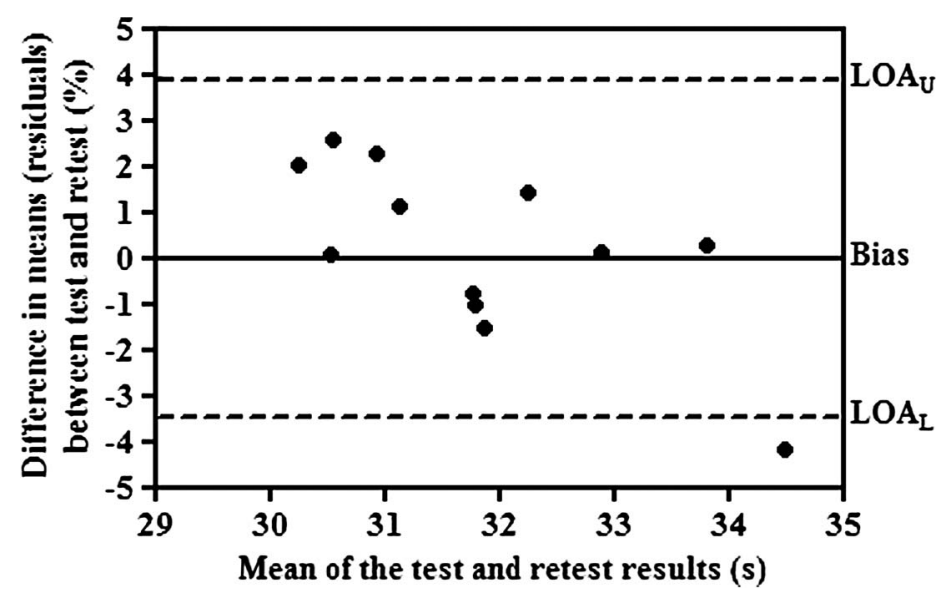

Figure 2. Differences between line-drill (LD) test and retest measured against the average performance for the 2 test sessions. Differences are expressed as a percentage of the average of the LD test and retest. The bias line and the upper and lower $95 \%$ limits of agreement $\left(L O A_{\cup}\right.$ and $L O A_{L}$, respectively) are also presented.

\section{Validity}

Correlations between anaerobic indicators and $\mathrm{CA}$, estimated APHV, and basketball experience are summarized in Table 2. Correlations between $\mathrm{CA}$ and $\mathrm{PP}(r=0.36)$ and $\mathrm{MP}(r$ $=0.35)$ were significant $(p<$ $0.01)$ but moderate in magnitude. Corresponding correlations between estimated APHV and laboratory-based estimates of anaerobic performance were higher and significant $(p<0.01)$, PP $(r=-0.69)$ and MP $(r=-0.71)$. The negative correlations indicated higher PP and MP in earliermaturing players. In contrast, correlations of $\mathrm{CA}$ and estimated APHV with LD were low and not significant, $r=0.18$

\section{Results}

Characteristics of the total sample of youth basketball players are shown in Table 1 . All maturity offset values were positive except one, indicating that the sample was beyond the age at maximum growth rate in height during the adolescent spurt.

\section{Reliability}

The difference (mean of mean differences) between trials of the LD test was $0.2 \%(95 \% \mathrm{CI}-1.0$ to $1.4 \%)$, which corresponded to 0.05 seconds $(95 \% \mathrm{CI}-0.35-0.45$ seconds). The TEM was 0.44 seconds ( $95 \%$ CI $0.31-0.75$ seconds); the CV, 1.4\% (95\% CI 1.0-2.3\%); and the limit of agreement, $4.3 \%$ (Figure 2). The retest correlation was 0.91 (95\% CI $0.68-0.97)$.

TABLE 2. Correlations between indicators of anaerobic performance and age, training experience, and estimated age at peak height velocity $(\mathrm{APHV}) .{ }^{*} \dagger$

\begin{tabular}{lccc}
\hline & $\begin{array}{c}\text { Chronological } \\
\text { age }\end{array}$ & $\begin{array}{c}\text { Years of } \\
\text { formal training }\end{array}$ & APHV \\
\hline Line drill $\dagger$ & 0.18 & 0.13 & -0.19 \\
$\begin{array}{l}\text { WAnT peak } \\
\text { power }\end{array}$ & $0.36 \ddagger$ & 0.00 & $-0.69 \ddagger$ \\
$\begin{array}{c}\text { WAnT mean } \\
\text { power }\end{array}$ & $0.35 \ddagger$ & -0.07 & $-0.71 \ddagger$ \\
\hline
\end{tabular}

${ }^{*} \mathrm{WAnT}=$ Wingate Anaerobic Test.

$\dagger$ Signs are reversed because a lower time on the line drill indicates a better performance. $\ddagger p<0.01$. and $r=-0.19$, respectively. Neither LD nor WAnT was significantly correlated with years of training in basketball.

Correlations between the LD field test and PP and MP based on the 30 -second cycle ergometer test are presented in Table 3. Line-drill time and WAnT power outputs were significantly correlated $(p<0.01)$ : PP, $r=0.39$ and MP, $r=$ 0.43 , but the correlations were moderate at best. Controlling for CA and estimated APHV did not alter the correlations, but controlling for $\mathrm{CA}$ and body size increased the correlations somewhat: PP, $r=0.47$ and MP, $r=0.55$ $(p<0.01)$.

Comparisons of players by level of competition are summarized in Table 4. National-level players had

TABLE 3. Bivariate and partial correlations between the line-drill (LD) test and Wingate Anaerobic Test (WAnT) power outputs, controlling for chronological age (CA) and estimated age at peak height velocity (APHV), and for CA and body size.

\begin{tabular}{cccc}
\hline & & \multicolumn{2}{c}{ Partial correlation } \\
\cline { 3 - 4 } & $\begin{array}{c}\text { Bivariate } \\
\text { correlation }\end{array}$ & $\mathrm{CA}$, & $\mathrm{CA}$, stature, \\
& $\mathrm{APHV}$ & body mass \\
\hline $\begin{array}{c}\mathrm{LD} \text { vs. WAnT } \\
\text { peak power* } \\
\begin{array}{c}\mathrm{LD} \text { vs. WAnT } \\
\text { mean power }\end{array}\end{array}$ & $0.39 \dagger$ & $0.33 \dagger$ & $0.47 \dagger$ \\
\hline
\end{tabular}

*Signs are reversed because a lower time on the LD indicates a better performance.

$$
\dagger p<0.01 \text {. }
$$


TABLE 4. Comparison of anaerobic performance by competitive level and results of analyses of covariance (ANCOVAs) controlling for chronological age (CA) and estimated age at peak height velocity (APHV), and for CA, stature, and body mass.

\begin{tabular}{|c|c|c|c|c|c|c|c|c|c|c|}
\hline & \multicolumn{2}{|c|}{$\begin{array}{l}\text { National level } \\
\quad(n=24)\end{array}$} & \multicolumn{2}{|c|}{$\begin{array}{l}\text { Local level } \\
\quad(n=52)\end{array}$} & \multirow[b]{2}{*}{$F$} & \multirow[b]{2}{*}{$\eta^{2}$} & \multicolumn{4}{|c|}{ ANCOVA } \\
\hline & Mean & $S D$ & Mean & $S D$ & & & CA, APHV & $\eta^{2}$ & $\mathrm{CA}$, stature, body mass & $\eta^{2}$ \\
\hline Line drill (s) & 30.15 & 0.94 & 31.42 & 1.39 & $16.59^{*}$ & 0.183 & $10.83 \dagger$ & 0.131 & $12.89^{*}$ & 0.154 \\
\hline Peak power (W) & 746.5 & 113.3 & 594.2 & 107.6 & $31.83^{*}$ & 0.301 & 0.74 & 0.010 & 0.38 & 0.005 \\
\hline Mean power $(\mathrm{W})$ & 639.8 & 97.3 & 496.0 & 79.4 & $33.26^{*}$ & 0.310 & 0.88 & 0.012 & 0.10 & 0.001 \\
\hline
\end{tabular}

${ }^{*} p<0.01$
${ }_{\dagger} p<0.05$

significantly better anaerobic performances than local-level players $(p<0.01)$. Controlling for CA and body size and for $\mathrm{CA}$ and estimated APHV with ANCOVA indicated significant differences between national and local players for the LD test but not for WAnT power outputs.

\section{Discussion}

Given the popularity of LDs as a conditioning exercise in basketball training (18), the reliability and validity of the LD protocol under standardized conditions were examined in the context of youth basketball. The running field test of anaerobic performance had high reliability and acceptable validity. The LD test is thus an appropriate field test of anaerobic fitness in adolescent basketball players.

The test-retest correlation in the present study, $r=0.91$, was consistent with that reported by Harley et al. (16) for 10 subjects, $r=0.93$. However, information on measurement procedures and subject characteristics was not reported. The $\mathrm{CV}$ in the present study, $1.4 \%$, was identical with that reported by Harley et al. (16). Although the LD test had good reliability in the subsample of 12 players, performances tended to decline slightly, on average, from the first to the second trials. Additionally, the plot of residuals in the reliability analysis (Figure 2) showed a tendency for residuals to become more scattered about the zero line among athletes with better times. Familiarity with the testing protocol may have contributed to the high reliability because the test is often described as a conditioning exercise for basketball (18). Intra- and interindividual differences in motivation and fatigue are potential factors that need to be considered when using this anaerobic testing procedure. The low CV, 1.4\% (95\% CI 1.0-2.3\%), suggests relatively little within-subject variation between trials. Both intra- and interindividual variation are reflected in the retest correlation, which indicates the maintenance of group position (rank order) on the tests. Thus, simply reporting the correlation may be an insufficient indicator of reliability (9).
The cross-validity of the LD test was verified by comparison with the WAnT, which is commonly considered the reference for anaerobic testing. This test has been used extensively and in a variety of settings with pediatric populations spanning childhood through adolescence $(5,38)$. In these contexts, the test was highly reliable and sensitive. Adolescent basketball players in the present study generated values of PP and MP (Table 1) comparable to those for male subjects of corresponding ages $(1,3,7,24)$, allowing for variation in protocols and instruments. Subjects in the present study, however, presented lower values in both PP and MP compared to older adolescent or young adult basketball players $17-19$ years of age $(2,18)$. This suggests that age per se, late adolescent growth in muscle mass, and perhaps the accumulated effects of training may contribute to the variation in results.

Several authors have suggested that no single test best measures all aspects of anaerobic performance $(10,41)$. However, in adults, the metabolic profile of the WAnT is highly anaerobic and is dominated by glycolysis and creatine phosphate breakdown with a minor aerobic component (8). The present data showed a moderate correlation between performance in the WAnT and the LD test, in particular with MP, suggesting that the LD test may measure in part the same anaerobic properties as WAnT. Although the time to complete the LD test was similar to the protocol of the WAnT, the association between the field and laboratory tests may be influenced by differences in movement patterns, running vs. cycling. A similar observation between LD and MP was noted among 17-year-old basketball players (18).

The construct validity of a test may be assessed by comparing two different groups of subjects with different abilities (39). The narrow range of variance in $\mathrm{LD}$ values reported in the literature may raise questions about the potential value of the protocol to distinguish athletes by level of ability. The best performances on the LD test among players in the present study were within the range of means (28-30 seconds) reported in several studies of 16- to 
19-year-old basketball players $(2,11,15,17,18,31)$. Errors associated with the use of manual chronometers and of different shuttle distances potentially limit generalizations among reported data for the LD test. Photoelectric cells were used in LD testing in the present study and the adolescent basketball players were distinguished by playing ability on the basis of the LD test. The value of this protocol in distinguishing athletes by playing level was highlighted by its independence of estimated maturity status (Table 4). This is relevant because growth- and maturity-related changes during adolescence need to be considered when evaluating test results and outcomes of talent identification and development programs (32).

Correlations between indicators of anaerobic performance and estimated APHV were negative (Table 2), suggesting that earlier-maturing players have better anaerobic performances under laboratory conditions. In contrast, the correlation between LD performance and estimated APHV was low and not significant (Table 2). The issue of maturity-associated variation in anaerobic performance has not received much attention (42). Some evidence indicated an increase in PP and MP in boys classified as prepubertal, pubertal, and mature (13). However, CA varied within and among the 3 maturity groups and was not statistically controlled in the analysis. This is relevant because anaerobic performance improves with age during adolescence independently of pubertal status (28). It is likely that maturity exerts an influence on anaerobic performance via body size and muscle mass. Within a given age-group of adolescent boys, those advanced in maturation are, on average, taller and heavier and have a larger muscle mass than boys later in maturation (28). Some limited data for adolescent boys suggest an independent maturity effect on PP and MP that was more apparent in the later stages of sexual maturation, specifically, stages 4 and 5 of pubic hair development (4). Given the age range of the present sample of basketball players, the negative association between estimated APHV and PP and MP was consistent with these observations.

Training experience in basketball was not associated with the 3 indicators of anaerobic performance (Table 2). It is likely that experience expressed in years was not a sufficiently sensitive indicator of training, that is, intensity and regularity. Potential effects of training on anaerobic performance are also likely confounded by normal growth and maturation during male adolescence.

\section{Practical Applications}

The LD test is a sport-specific field test of anaerobic performance in adolescent basketball players. The test provided reliable data and successfully differentiated adolescent players by competitive level. Moreover, LD performance was independent of estimated maturity status in the sample of players 14-16 years of age. As such, the results should be of interest to coaches, sport scientists, and others involved in the selection and development of youth basketball players.

\section{ACKNOWLeDgments}

This research was supported by Fundação para a Ciência e a Tecnologia (PTDC/DES/70918/2006 and SFRH/BD/ 41647/2007). The collaboration of the Federação Portuguesa de Basquetebol is acknowledged by the authors.

\section{REFERENCES}

1. Almuzaini, KS. Muscle function in Saudi children and adolescents: Relationship to anthropometric characteristics during growth. Pediatr Exerc Sci 19: 319-333, 2007.

2. Apostolidis, N, Nassis, GP, Bolatoglou, T, and Geladas, ND. Physiological and technical characteristics of elite young basketball players. J Sports Med Phys Fitness 44: 157-163, 2004.

3. Armstrong, N, Welsman, JR, and Chia, MY. Short term power output in relation to growth and maturation. Br J Sports Med 35: $118-124,2001$

4. Armstrong, N, Welsman, JR, Williams, CA, and Kirby, BJ. Longitudinal changes in young people's short-term power output. Med Sci Sports Exerc 32: 1140-1145, 2000.

5. Bar-Or, O. The Wingate anaerobic test. An update on methodology, reliability and validity. Sports Med 4: 381-394, 1987.

6. Ben Abdelkrim, N, El Fazaa, S, and El Ati, J. Time-motion analysis and physiological data of elite under-19-year-old basketball players during competition. Br J Sports Med 41: 69-75, 2007.

7. Beneke, R, Hutler, M, and Leithauser, RM. Anaerobic performance and metabolism in boys and male adolescents. Eur JAppl Physiol 101: 671-677, 2007

8. Beneke, R, Pollmann, C, Bleif, I, Leithauser, RM, and Hutler, M. How anaerobic is the Wingate Anaerobic Test for humans? Eur $J$ Appl Physiol 87: 388-392, 2002.

9. Bland, JM and Altman, DG. Statistical methods for assessing agreement between two methods of clinical measurement. Lancet 1: 307-310, 1986.

10. Bosco, C, Luhtanen, P, and Komi, PV. A simple method for measurement of mechanical power in jumping. Eur J Appl Physiol Occup Physiol 50: 273-282, 1983.

11. Castagna, C, Impellizzeri, FM, Rampinini, E, D’Ottavio, S, and Manzi, V. The Yo-Yo intermittent recovery test in basketball players. J Sci Med Sport 11: 202-208, 2008.

12. Elferink-Gemser, MT, Visscher, C, Lemmink, KA, and Mulder, TW Relation between multidimensional performance characteristics and level of performance in talented youth field hockey players. $J$ Sports Sci 22: 1053-1063, 2004.

13. Falk, B and Bar-Or, O. Longitudinal changes in peak aerobic and anaerobic mechanical power of circumpubertal boys. Pediatr Exerc Sci 5: 318-331, 1993.

14. Federação Portuguesa de Basquetebol [Portuguese basketball Federation] Web site. Lisbon: 2009: Federação Portuguesa de Basquetebol. Available at: http://www.fpb.pt. Accessed January 10, 2009.

15. Graham, JE, Douglas Boatwright, J, Hunskor, MJ, and Howell, DC Effect of active vs. passive recovery on repeat suicide run time. J Strength Cond Res 17: 338-341, 2003.

16. Harley, R, Doust, J, and Mills, S. Basketball. In: Sport and Exercise Physiology Testing Guidelines: Volume I-Sport Testing. Winter, E, Jones, A, Davidson, R, Bromley, P, and Mercer, T, eds. London: Routledge, 2007, pp. 232-240.

17. Hoare, DG. Predicting success in junior elite basketball players-The contribution of anthropometric and physiological attributes. $J \mathrm{Sci}$ Med Sport 3: 391-405, 2000.

18. Hoffman, JR, Epstein, S, Einbinder, M, and Weinstein, Y. A comparison between the Wingate anaerobic power test to both vertical jump and line drill tests in basketball players. J Strength Cond Res 14: 261-264, 2000. 
19. Hoffman, JR, Tenenbaum, G, Maresh, CM, and Kraemer, WJ. Relationship between athletic performance tests and playing time in elite college basketball players. J Strength Cond Res 10: 67-71, 1996.

20. Hopkins, WG. Measures of reliability in sports medicine and science. Sports Med 30: 1-15, 2000.

21. Hopkins, WG. A scale of magnitudes for effect statistics, 2002. Available at: http://www.sportsci.org/resource/stats/index.html. Accessed March 25, 2009.

22. Impellizzeri, FM, Rampinini, E, Castagna, C, Bishop, D, Ferrari Bravo, D, Tibaudi, A, and Wisloff, U. Validity of a repeated-sprint test for football. Int J Sports Med 29: 899-905, 2008.

23. Inbar, O, Bar-Or, O, and Skinner, JS. The Wingate Anaerobic Test. Champaign, IL: Human Kinetics, 1996.

24. Kasabalis, A, Douda, H, and Tokmakidis, SP. Relationship between anaerobic power and jumping of selected male volleyball players of different ages. Percept Mot Skills 100: 607-614, 2005.

25. Krustrup, P, Mohr, M, Nybo, L, Jensen, JM, Nielsen, JJ, and Bangsbo, J. The Yo-Yo IR2 test: Physiological response, reliability, and application to elite soccer. Med Sci Sports Exerc 38: 1666-1673, 2006.

26. Lohman, TG, Roche, AF, and Martorell, R. Anthropometric Standardization Reference Manual. Champaign, IL: Human Kinetics, 1988.

27. Malina, RM. Anthropometry. In: Physiological Assessment of Human Fitness. Maud PJ and Foster, C. eds. Champaign, IL: Human Kinetics, 1995, pp. 205-220.

28. Malina, RM, Bouchard, C, and Bar-Or, O. Growth, Maturation, and Physical Activity Champaign, IL: Human Kinetics, 2004.

29. McInnes, SE, Carlson, JS, Jones, CJ, and McKenna, MJ. The physiological load imposed on basketball players during competition. J Sports Sci 13: 387-397, 1995.

30. Mirwald, RL, Baxter-Jones, AD, Bailey, DA, and Beunen, GP. An assessment of maturity from anthropometric measurements. Med Sci Sports Exerc 34: 689-694, 2002.

31. Montgomery, PG, Pyne, DB, Hopkins, WG, and Minahan, CL. Seasonal progression and variability of repeat-effort line-drill performance in elite junior basketball players. J Sports Sci 26: 543-550, 2008.

32. Pearson, DT, Naughton, GA, and Torode, M. Predictability of physiological testing and the role of maturation in talent identification for adolescent team sports. J Sci Med Sport 9: 277-287, 2006.

33. Reilly, T, Williams, AM, Nevill, A, and Franks, A. A multidisciplinary approach to talent identification in soccer. J Sports Sci 18 : 695-702, 2000.

34. Sallet, P, Perrier, D, Ferret, JM, Vitelli, V, and Baverel, G. Physiological differences in professional basketball players as a function of playing position and level of play. J Sports Med Phys Fitness 45: 291-294, 2005.

35. Seminick, D. Tests and measurements: The line drill test. NSCA J 12: 47-49, 1990.

36. Spencer, M, Fitzsimons, M, Dawson, B, Bishop, D, and Goodman, C. Reliability of a repeated-sprint test for field-hockey. J Sci Med Sport 9: 181-184, 2006.

37. Stone, NM and Kilding, AE. Aerobic conditioning for team sport athletes. Sports Med 39: 615-642, 2009.

38. Sutton, NC, Childs, DJ, Bar-Or, O, and Armstrong, N. A nonmotorized treadmill test to assess children's short-term power output. Pediatr Exerc Sci 12: 91-100, 2000.

39. Thomas, JR and Nelson, JK. Research Methods in Physical Activity. Champaign, IL: Human Kinetics, 2001.

40. Vaeyens, R, Malina, RM, Janssens, M, Van Renterghem, B, Bourgois, J, Vrijens, J, and Philippaerts, RM. A multidisciplinary selection model for youth soccer: The Ghent Youth Soccer Project. Br J Sports Med 40: 928-934, 2006.

41. Vandewalle, H, Peres, G, and Monod, H. Standard anaerobic exercise tests. Sports Med 4: 268-289, 1987.

42. Van Praagh, E and Dore, E. Short-term muscle power during growth and maturation. Sports Med 32: 701-728, 2002.

43. Wragg, CB, Maxwell, NS, and Doust, JH. Evaluation of the reliability and validity of a soccer-specific field test of repeated sprint ability. Eur J Appl Physiol 83: 77-83, 2000. 